\title{
Erratum to: Thyroid hormone levels as a predictor of mortality in intensive care patients: a comparative prospective study
}

\author{
Adnan Tas, Tamer Tetiker, Yavuz Beyazit, Hacer Celik, Yusuf Yesil
}

Published online: 28 March 2013

(c) Springer-Verlag Wien 2013

Erratum to: Wien Klin Wochenschr (2012) 124: 154-159. DOI 10.1007/s00508-012-0125-1

The authors of Tas et al. (2012) have brought to our attention corrections that need to be made to the "Patients and methods" section in their paper. The first sentence "This study was undertaken in the Medical ICU Department of the Faculty of Medicine at Çukurova University between
January 2007 and January 2009 with the approval of the Local Ethics committee." should have read as a follows:

"This study was undertaken in the Medical ICU Department of the Faculty of Medicine at Çukurova University between January 2004 and January 2006 with the approval of the Local Ethics committee."

We apologize to our readers for this mistake.

The online version of the original article can be found under doi:10.1007/s00508-012-0125-1

\footnotetext{
A. Tas $(\square)$

Department of Gastroenterology, Ankara Education and Research

Hospital, Ankara, Turkey

E-Mail: dradnantas@gmail.com

T. Tetiker

Department of Endocrinology, Faculty of Medicine Çukurova

University, Adana, Turkey

Y. Beyazit · Y. Yesil

Department of Gastroenterology, Türkiye Yüksek lhtisas Hospital, Ankara, Turkey

H. Celik

Department of Chest Diseases, Osmaniye Public Hospital,

Osmaniye, Turkey
} 